\title{
Impact of Intervention Program on Sexual Behavior, HIV and Sexually Transmitted Infections among Self-Identified Men Who Have Sex with Men in Select Districts of Andhra Pradesh, India
}

\author{
Venkaiah Kodavalla1 ${ }^{*}$, Hari Kumar Rachakulla1, Hemalatha Rajkumar1, \\ Sarede Paleswara Vara Prasad', Srinivasan Kallam², \\ Brahmam Ginnela Narasimhachary ${ }^{1}$ \\ ${ }^{1}$ National Institute of Nutrition (NIN), Hyderabad, India \\ ${ }^{2} \mathrm{FHI}$ 360, New Delhi, India \\ Email: ${ }^{*}$ kodalivenkaiah@yahoo.com
}

Received 26 September 2014; revised 1 November 2014; accepted 25 November 2014

Copyright (C) 2014 by authors and Scientific Research Publishing Inc.

This work is licensed under the Creative Commons Attribution International License (CC BY). http://creativecommons.org/licenses/by/4.0/

(c) (i) Open Access

\begin{abstract}
The study aimed to assess the impact of Avahan intervention program on risk behaviors. Knowledge of HIV/STIs and their prevalence among self-identified men who have sex with men (MSM) in four select districts of Andhra Pradesh, India, covers about 1600 respondents in each of the two rounds. The response rates of MSM in $\mathrm{R} 1$ and $\mathrm{R} 2$ were about $70 \%$. Higher numbers of MSM in $\mathrm{R2}$ had literacy level of $\geq 10$ th class, were either students, self-employed/business men and belonged to 20 - 24 years. Higher proportion of MSM in R2 reportedly had knowledge of HIV and its prevention, at least two signs/symptoms of STIs in men. Significantly higher numbers of MSM in R2 were exposed to programme interventions and consistent condom users. HIV prevalence declined significantly in one district, increased in one and remained similar in two districts. The prevalence of STIs decreased significantly in two districts, while remained similar in the other.
\end{abstract}

\section{Keywords}

MSM, Risk Behavior, HIV-AIDS, STI, Condom Use

\footnotetext{
Corresponding author.
} 


\section{Introduction}

India, the second-most populous country, was experiencing a highly varied HIV epidemic, in the past two decades. HIV in India is concentrated among certain "high-risk" populations like Injecting Drug Users (IDUs), Men having Sex with Men (MSM) and Female Sex Workers (FSWs). Targeted interventions (TIs) with these populations have been one of the major aspects of India's National AIDS Control Programme (NACP). The recent HIV estimates showed a reduction in Adult HIV prevalence from $0.41 \%$ in the year 2000, to $0.36 \%$ in 2006 and to $0.31 \%$ in 2009. The estimated number of new annual HIV infections declined from $0.27 \mathrm{~m}$ in 2000 to $0.12 \mathrm{~m}$ in 2009 [1].

However, Andhra Pradesh (AP) state remains to be critical in the spread and control of HIV epidemic, as it has second highest estimated adult HIV prevalence of $0.9 \%$, with Manipur at $1.40 \%$. While India had an estimated $2.4 \mathrm{~m}$ people living with HIV/AIDS in 2009, the state of AP tops the list with about $0.5 \mathrm{~m}$; followed by $0.42 \mathrm{~m}$ in Maharashtra, $0.25 \mathrm{~m}$ in Karnataka and $0.15 \mathrm{~m}$ in Tamil Nadu. Of the estimated people living with HIV/AIDS, about $0.93 \mathrm{~m}(39 \%)$ is women [1].

HIV prevalence among Men having Sex with Men (MSM) in AP was high at 17.04\% in 2007, with an increase from $10.25 \%$ in 2006. Sentinel surveillance data of 2007 also showed Andhra Pradesh as the only state with $>1 \%$ prevalence among ANC attendees [2].

Targeted Interventions carried out by the Andhra Pradesh AIDS Control Society (APSACS) and Avahan by Bill and Melinda Gates Foundation (BMGF) are the two major HIV/AIDS prevention programs currently in operation in the state. The APSACS in partnership with NACO has been implementing HIV prevention, care and treatment programs since 1999, which have resulted in significant gains. However, the epidemic continues to be a cause for major concern. The HIV sentinel surveillance round in Andhra Pradesh during 2007 revealed that, across the state, the prevalence levels continue to show an upward trend, pointing to a need for intensified prevention efforts. There is an increasing recognition of the substantial role that MSM behaviors have played in HIV epidemics in Indian settings [3]-[13]. However, limited data are available in India on MSM except for some small studies [11] [14]-[19].

In this backdrop, the present paper utilizes the data from "Integrated Behavioral and Biological Assessment" (IBBA) conducted at two different time points, Round-1 in 2006-2007 and Round-2 in 2009 in select districts of Andhra Pradesh to analyze and present the impact of these Interventions on the sexual behaviours, STI prevalence and HIV prevalence in the state of Andhra Pradesh.

\section{Methods}

\section{Ethical Approval}

\section{Setting}

The Integrated Biological and Behavioral Assessment (IBBA), was a cross-sectional study, conducted by adopting same protocol, questionnaires, Methodology, sampling design and sample size during Round-1 and Round-2 in the districts of East Godavari, Guntur, Hyderabad and Visakhapatnam. A sample size of 400 subjects per district per round was arrived to detect an absolute difference of $15 \%$ or more from an assumed value of $50 \%$ of consistent condom use (use of condom at every sex act) by the target population with 95\% confidence, $90 \%$ power and design effect of 1.7 .

A probability based sampling method with a varied sampling approach was used to select primary sampling units, the sites. Time Location Cluster Sampling approach was used taking into account the different sub-populations that congregate in a single location at different time points of a day or on different days of a week [20].

This study collated information on socio-demographic characteristics, sexual behaviors, risk perception, prevalence of STI and HIV among self-identified men who have sex with men (MSM) population.

The inclusion criteria were, any male or hijra, self-identified MSM, aged 18 years or above, who had any type of sex (oral, manual, or penetrative), paid or unpaid, with another male in the last one month.

The data collected was scrutinized, fed in to computer by double entry technique to rectify entry mistakes if any and was cleaned using range and consistency checks in order to develop database. Appropriate weights were calculated and applied at district levels for unequal selection probability. These weights were used for statistical analysis of all the parameters [20]. The distributions of data at different time points in the study districts were compared using Pearson $\chi^{2}$. 
Sexual partners of MSM were categorized into 1) Paying male partners (having a partners who paid to have sex), 2) Paid male partners (Paid to have sex with partners), 3) Non-commercial, non-regular male partners 4) Regular male partners, 5) Regular female partners and 6) Paid female Partners. Consistent condom use was defined as using condom at every sex act; and last time condom use was defined as use of condom during the last sex act.

The study was approved by the Institutional ethical committee of National Institute of Nutrition. Written informed consent was obtained from the participants of the study, with a provision to maintain confidentiality.

Community monitoring board and Community advisory boards were established in each of the district with local NGOs, community members, local officials and leaders as members to communicate to the community about the study, to create an ambience of mutual trust, to help and ensure the protection of rights and physical \& psychological well-being of the respondents.

\section{Results}

Response rate of the participants in the study ranged from a low 56\% in Vishakapatnam to a high $70 \%$ in E. Godavari. Response rates were relatively less in R2 compared to R1 in all the districts, except E. Godavari where it was similar (data not shown).

\subsection{Profile of MSM}

District wise profile of MSM population in both rounds of IBBA is presented in Table 1. Significantly higher proportion (70\%) of young (20 - 29 years) MSM participated in R2 in E. Godavari district compared to R1, while in other three districts the age distributions of MSM were comparable in both rounds. The mean age was significantly lower in E. Godavari district in R2 (27.3 years) compared to 29.6 in R1, with no significant differences in other districts. In general, significantly $(\mathrm{p}<0.01)$ higher proportion of MSM had literacy level of $10^{\text {th }}$ standard or above in R2, compared to R1. The proportion of students, self-employed/business and service class MSM was relatively higher in R2. Students' representation ranged from $6.3 \%$ to $14.3 \%$ in R2 across districts compared to $2.5 \%$ to $5.9 \%$ in R1.

Current marital status of MSM did not vary significantly between R1 and R2. Majority of MSM (ranging from $68 \%$ to $96 \%$ ) in both the rounds across all districts reported that they were staying with their families.

A majority (93\% to $100 \%)$ of the MSM who participated in both the IBBA rounds were localities (belonging to the place where study is done). Most of the MSM (about 70\% - 90\%) were staying with their families, both in R1 \& R2. In the district of E. Godavari, the proportion of those staying with male sex partner was relatively higher in R2, compared to R1 (9\% vs. $0.2 \%$ ).

The proportion of those who had undergone circumcision remained low $(1 \%-4 \%)$ in the districts of E. Godavari and Visakhapatnam during both the rounds. While it continued to be high in Guntur (about 20\%), significant $(\mathrm{p}<0.01)$ decline was observed in Hyderabad (from $19 \%$ to $8 \%$ ).

A majority of the respondents $(60 \%-80 \%)$ reportedly had the sexual debut at the age of $15-19$ years during both the rounds. The proportion of those who had sexual debut at the age $<15$ years tended to decrease in all the districts.

\subsection{Types of Partners}

Distribution (\%) of MSM by the type of partners in different districts is presented in Table 2. The percent distributions of MSM according to type of main sexual partner between R1 and R2 were significantly different in all the districts except Guntur.

The proportion of MSM having only male as main sexual partner increased significantly $(p<0.01)$ from R1 to R2 in E. Godavari (33\% to 44\%), Hyderabad (32\% to 49\%). While similar trend was observed in Guntur, it tended to decrease in the district of Visakhapatnam (53\% to 36\%). The proportion of MSM having female as a main sexual partner, was higher in R2 compared to R1 in the districts of E. Godavari and Visakhapatnam, while it declined in the districts of Guntur and Hyderabad. The proportion of MSM having both male \& female as a main sexual partners, was lower in R2 compared to R1 in the districts of E. Godavari and Visakhapatnam, while it increased in the districts of Guntur and Hyderabad. 
Table 1. Profile of MSM-by districts.

\begin{tabular}{|c|c|c|c|c|c|c|c|c|}
\hline \multirow{2}{*}{ Particulars } & \multicolumn{2}{|c|}{ East Godavari } & \multicolumn{2}{|c|}{ Guntur } & \multicolumn{2}{|c|}{ Hyderabad } & \multicolumn{2}{|c|}{ Visakhapatnam } \\
\hline & $\mathrm{R} 1$ & $\mathrm{R} 2$ & $\mathrm{R} 1$ & $\mathrm{R} 2$ & $\mathrm{R} 1$ & $\mathrm{R} 2$ & $\mathrm{R} 1$ & $\mathrm{R} 2$ \\
\hline $\mathrm{n}$ & 405 & 400 & 407 & 404 & 403 & 405 & 406 & 399 \\
\hline \multicolumn{9}{|c|}{ Current Age (Years) } \\
\hline$<20$ & 6.7 & 1.6 & 4.7 & 4.0 & 6.1 & 4.3 & 13.7 & 10.1 \\
\hline $20-24$ & 27.7 & 36.3 & 41.6 & 28.1 & 33.9 & 43.1 & 39.3 & 40.9 \\
\hline $25-29$ & 25.3 & 37.0 & 21.1 & 26.7 & 27.6 & 28.3 & 25.4 & 22.3 \\
\hline $30-34$ & 14.3 & 12.4 & 13.5 & 20.7 & 13.1 & 11.8 & 11.0 & 8.1 \\
\hline $35-39$ & 10.5 & 5.6 & 9.6 & 8.3 & 9.7 & 9.2 & 4.9 & 9.3 \\
\hline $40-44$ & 5.3 & 3.5 & 6.0 & 6.2 & 5.2 & 2.3 & 2.2 & 3.8 \\
\hline$\geq 45$ & 10.1 & 3.6 & 3.3 & 6.0 & 4.1 & 1.0 & 3.5 & 5.3 \\
\hline p-Value & \multicolumn{2}{|c|}{0.02} & \multicolumn{2}{|c|}{0.217} & \multicolumn{2}{|c|}{0.170} & \multicolumn{2}{|c|}{0.612} \\
\hline Mean Age (Yrs) & 29.6 & 27.3 & 27.3 & 28.9 & 27.8 & 26.2 & 25.5 & 27.0 \\
\hline Median Age (Yrs) & 27.8 & 25.0 & 25.0 & 27.9 & 26.0 & 25.0 & 24.0 & 24.0 \\
\hline \multicolumn{9}{|c|}{ Educational Status } \\
\hline Illiterate & 21.5 & 12.8 & 34.9 & 21.1 & 21.4 & 13.9 & 16.4 & 25.8 \\
\hline $1^{\text {st }}$ to $5^{\text {th }}$ Standard & 15.5 & 7.8 & 14.3 & 7.7 & 14.3 & 2.5 & 16.3 & 6.3 \\
\hline $6^{\text {th }}$ to $10^{\text {th }}$ Standard & 44.8 & 36.7 & 38.5 & 37.1 & 43.3 & 42.5 & 54.9 & 42.1 \\
\hline Above $10^{\text {th }}$ Standard & 18.3 & 42.6 & 12.3 & 34.1 & 21.0 & 41.1 & 12.3 & 25.8 \\
\hline p-value & \multicolumn{2}{|c|}{0.002} & \multicolumn{2}{|c|}{0.000} & \multicolumn{2}{|c|}{0.000} & \multicolumn{2}{|c|}{0.000} \\
\hline \multicolumn{9}{|c|}{ Main Source of Income } \\
\hline Unemployed & 9.6 & 1.2 & 1.1 & 0.6 & 5.5 & 0.4 & 13.4 & 2.1 \\
\hline Student & 3.0 & 6.3 & 4.2 & 10.0 & 2.5 & 14.3 & 5.9 & 7.3 \\
\hline Self Employed/Business & 25.0 & 29.1 & 12.6 & 31.3 & 9.0 & 20.2 & 19.8 & 24.2 \\
\hline Service & 19.7 & 33.2 & 17.2 & 23.7 & 42.0 & 40.2 & 18.2 & 24.5 \\
\hline Labourer/Transport Workers & 30.3 & 22.6 & 45.6 & 31.4 & 26.8 & 11.1 & 40.1 & 35.4 \\
\hline Massager/Pun & 6.7 & 4.2 & 3.6 & 3.1 & 8.1 & 13.2 & 1.5 & 3.6 \\
\hline Others & 5.5 & 3.5 & 15.5 & 0.0 & 6.1 & 0.7 & 1.1 & 2.9 \\
\hline p-Value & \multicolumn{2}{|c|}{0.01} & \multicolumn{2}{|c|}{0.000} & \multicolumn{2}{|c|}{0.000} & \multicolumn{2}{|c|}{0.007} \\
\hline \multicolumn{9}{|c|}{ Current Marital Status } \\
\hline Never Married & 52.8 & 59.1 & 38.2 & 47.2 & 70.4 & 73.3 & 61.2 & 73.0 \\
\hline Currently Married & 46.4 & 40.7 & 60.0 & 51.7 & 26.8 & 26.7 & 38.5 & 26.2 \\
\hline Divorced/Widowed & 0.6 & 0.2 & 1.4 & 1.2 & 2.3 & 0.1 & 0.3 & 0.8 \\
\hline Others & 0.2 & - & 0.4 & 0.0 & 0.4 & 0.7 & 0.0 & 0.0 \\
\hline p-Value & \multicolumn{2}{|c|}{0.42} & \multicolumn{2}{|c|}{0.222} & \multicolumn{2}{|c|}{0.045} & & \\
\hline & & & ving $A$ & ement & & & & \\
\hline Alone & 10.6 & 3.2 & 3.1 & 6.0 & 23.3 & 10.7 & 4.1 & 3.1 \\
\hline With Family & 88.3 & 79.9 & 93.4 & 92.9 & 67.6 & 77.6 & 95.4 & 96.3 \\
\hline With Friends/In Hostel & 0.6 & 1.3 & 0.8 & 0.6 & 5.4 & 8.8 & 0.3 & 0.2 \\
\hline With Male Sex Partner & 0.2 & 8.7 & 2.1 & 0.4 & 3.3 & 2.4 & 0.2 & 0.4 \\
\hline Others & 0.3 & 6.9 & 0.6 & 0.0 & 0.4 & 0.5 & 0.0 & 0.0 \\
\hline p-Value & & & & & & & & \\
\hline
\end{tabular}




\section{Continued}

\begin{tabular}{|c|c|c|c|c|c|c|c|c|}
\hline \multicolumn{9}{|c|}{ Residential Status } \\
\hline Localite & 92.8 & 99.9 & 99.5 & 99.9 & 97.4 & 99.8 & 99.6 & 95.4 \\
\hline Non-Localite & 7.2 & 0.1 & 0.5 & 0.1 & 2.6 & 0.2 & 0.4 & 4.6 \\
\hline p-Value & \multicolumn{2}{|c|}{0.00} & \multicolumn{2}{|c|}{0.04} & \multicolumn{2}{|c|}{0.001} & \multicolumn{2}{|c|}{0.028} \\
\hline \multicolumn{9}{|c|}{ Circumcised } \\
\hline No & 95.6 & 97.7 & 80.0 & 81.9 & 81.3 & 91.9 & 98.8 & 96.5 \\
\hline Yes & 4.4 & 2.3 & 20.0 & 18.1 & 18.7 & 8.1 & 1.2 & 3.5 \\
\hline p-Value & \multicolumn{2}{|c|}{0.13} & \multicolumn{2}{|c|}{0.77} & \multicolumn{2}{|c|}{0.003} & \multicolumn{2}{|c|}{0.032} \\
\hline \multicolumn{9}{|c|}{ Age at Sexual Debut (Years) } \\
\hline$<15$ & 7.0 & 5.1 & 16.8 & 10.9 & 33.1 & 20.7 & 17.4 & 9.2 \\
\hline $15-19$ & 71.6 & 80.5 & 74.2 & 70.2 & 57.6 & 64.6 & 78.0 & 80.1 \\
\hline $20-24$ & 20.0 & 12.5 & 8.1 & 17.8 & 8.5 & 13.8 & 4.4 & 10.5 \\
\hline$\geq 25$ & 1.4 & 1.8 & 1.0 & 1.1 & 0.9 & 0.8 & 0.2 & 0.2 \\
\hline p-Value & \multicolumn{2}{|c|}{0.14} & \multicolumn{2}{|c|}{0.03} & \multicolumn{2}{|c|}{0.014} & \multicolumn{2}{|c|}{0.066} \\
\hline Mean Age at First Sex (Yrs) & 17.5 & 17.5 & 16.4 & 17.0 & 15.6 & 16.5 & 16.1 & 17.0 \\
\hline Median Age at First Sex (Yrs) & 18.0 & 18.0 & 16.0 & 17.0 & 15.0 & 17.0 & 16.0 & 17.0 \\
\hline
\end{tabular}

Table 2. Distribution (\%) of MSM by type of partners-by districts.

\begin{tabular}{|c|c|c|c|c|c|c|c|c|}
\hline \multirow{2}{*}{ Particulars } & \multicolumn{2}{|c|}{ East Godavari } & \multicolumn{2}{|c|}{ Guntur } & \multicolumn{2}{|c|}{ Hyderabad } & \multicolumn{2}{|c|}{ Visakhapatnam } \\
\hline & $\mathrm{R} 1$ & $\mathrm{R} 2$ & $\mathrm{R} 1$ & $\mathrm{R} 2$ & $\mathrm{R} 1$ & $\mathrm{R} 2$ & $\mathrm{R} 1$ & $\mathrm{R} 2$ \\
\hline \multicolumn{9}{|c|}{ Type of main sexual partners } \\
\hline Only male partner & 33.2 & 43.7 & 15.5 & 22.8 & 31.7 & 48.9 & 52.9 & 36.2 \\
\hline Only female partner & 11.1 & 22.7 & 42.2 & 32.2 & 26.6 & 16.0 & 1.0 & 12.7 \\
\hline Both male and female partner & 44.2 & 26.9 & 23.7 & 26.2 & 7.5 & 14.0 & 45.8 & 24.9 \\
\hline No main sexual partner & 11.4 & 6.7 & 18.6 & 18.8 & 34.2 & 21.1 & 0.3 & 26.1 \\
\hline p-value & \multicolumn{2}{|c|}{0.005} & \multicolumn{2}{|c|}{0.198} & \multicolumn{2}{|c|}{0.000} & \multicolumn{2}{|c|}{0.000} \\
\hline \multicolumn{9}{|c|}{ Type of partners } \\
\hline Have regular male partner & 51.6 & 69.9 & 17.5 & 49.0 & 33.5 & 62.9 & 77.9 & 61.2 \\
\hline p-value & \multicolumn{2}{|c|}{0.02} & \multicolumn{2}{|c|}{0.00} & \multicolumn{2}{|c|}{0.00} & \multicolumn{2}{|c|}{0.02} \\
\hline Have regular hijra partner & 36.8 & 0.7 & 63.3 & 0.0 & 32.4 & 0.0 & 21.8 & 0.0 \\
\hline p-value & \multicolumn{2}{|c|}{0.00} & \multicolumn{2}{|c|}{0.00} & \multicolumn{2}{|c|}{0.00} & \multicolumn{2}{|c|}{0.00} \\
\hline Have paying male partner & 35.1 & 28.4 & 26.0 & 39.2 & 36.3 & 64.1 & 89.6 & 47.8 \\
\hline p-value & \multicolumn{2}{|c|}{0.45} & \multicolumn{2}{|c|}{0.02} & \multicolumn{2}{|c|}{0.00} & \multicolumn{2}{|c|}{0.00} \\
\hline Have paid male/hijra partner & 48.0 & 17.7 & 46.2 & 6.0 & 46.2 & 13.4 & 31.4 & 44.9 \\
\hline p-value & \multicolumn{2}{|c|}{0.001} & \multicolumn{2}{|c|}{0.00} & \multicolumn{2}{|c|}{0.00} & \multicolumn{2}{|c|}{0.03} \\
\hline $\begin{array}{l}\text { Have other non-paying } \\
\text { male/hijra partners }\end{array}$ & 88.6 & 95.4 & 87.5 & 97.0 & 88.8 & 93.6 & 95.4 & 92.6 \\
\hline p-value & \multicolumn{2}{|c|}{0.01} & \multicolumn{2}{|c|}{0.001} & \multicolumn{2}{|c|}{0.06} & \multicolumn{2}{|c|}{0.30} \\
\hline Have paid female partner & 39.7 & 0.7 & 63.6 & 1.3 & 31.8 & 0.2 & 27.5 & 22.5 \\
\hline p-value & \multicolumn{2}{|c|}{0.00} & \multicolumn{2}{|c|}{0.00} & & & & \\
\hline Have regular female partner & 55.3 & 49.5 & 65.9 & 58.4 & 34.1 & 30.0 & 46.8 & 37.6 \\
\hline p-value & & & & & 0.37 & 0.15 & 0.42 & 0.18 \\
\hline $\mathrm{n}$ & 405 & 400 & 407 & 404 & 403 & 405 & 406 & 399 \\
\hline
\end{tabular}


A majority (93\% to 97\%) of the MSM continued to have "other non-paying male/hijra partners" across the districts.

A significant $(\mathrm{p}<0.05)$ increase in the proportion of MSM having regular male partners and a significant $(\mathrm{p}<$ 0.01) decline in the proportion of MSM having a regular hijra partner was observed in all the study districts.

A significant $(\mathrm{p}<0.05)$ increase in the proportion of MSM having paying male partners was seen in Guntur (26\% to 39\%) and Hyderabad (36\% to 64\%) districts over the period. A significantly ( $<<0.05$ ) higher proportion (about 45\%) of MSM in Visakhapatnam district reportedly had paid male/hijra partners in R2, compared to R1 (31\%).

Less than 2\% of MSM in all study districts except Visakhapatnam (about 23\% - 28\%) reportedly had paid female partners. The proportion of MSM having female regular partners remained essential similar (30\% to 58\%) between the rounds, across the districts.

\subsection{Condom Use}

Percent distribution of MSM by consistent condom use and condom use during last sex act with different types of partners is presented in Table 3.

The consistent condom use with regular male partners was relatively higher and increased significantly $(\mathrm{p}<$ 0.01 ) in all the districts (from about $52 \%$ to $92 \%$ ) over the period.

The data on consistent condom use with paying male partners was collected only in R2, which R2 ranged from $79 \%$ to $89 \%$ across districts. Consistent condom use with paid male/hijra partners increased significantly (p < 0.01 ) $13 \%$ to $86 \%$ in E. Godavari; $40 \%$ to $98 \%$ on Guntur; $18 \%$ to $91 \%$ in Hyderabad and $1 \%$ to $95 \%$ in Visakhapatnam. Similarly, consistent condom use with non-paying male/hijra partners also increased significantly from $6 \%$ to $98 \%$ in E. Godavari; $32 \%$ to $75 \%$ on Guntur; $15 \%$ to $76 \%$ in Hyderabad and $1 \%$ to $90 \%$ in Visakhapatnam, over the period.

During R2, the consistent condom use and last time condom use with regular female partners was about 8\% $16 \%$ in Hyderabad, $13 \%$ - 14\% in Guntur \& E. Godavari and 32\% in Visakhapatnam.

Use of lubricants during anal sex increased significantly (p < 0.01) in Guntur (38\% to 64\%) and Hyderabad (34\% to $71 \%$ ) districts and decreased significantly in Visakhapatnam district (77\% to $45 \%$ ). Similar trend was observed with respect to E. Godavari district (41\% - 59\%). Proportion of MSM carrying condom at the time of interview was significantly higher in R2 (42\% to $54 \%)$ compared to R1 (7\% to $30 \%)$ in all the study districts except Visakhapatnam where it declined from $42 \%$ to $36 \%$. Reported condom breakage during past one month remained similar over the period and ranged from $6 \%-20 \%$ in all the districts, except in Visakhapatnam, wherein a significant decrease $(17 \%$ to $6 \%$ ) was reported. The proportion of MSM who reportedly had refused to have sex without condom with any male partner during the past 3 months increased significantly in R2 compared to R1 in all the districts except Visakhapatnam, wherein it decreased significantly (Table 3).

\subsection{Knowledge of STIS \& HIV/AIDS}

Percent distributions of MSM according to Knowledge of STI and HIV/AIDS by districts are given in Table 4. A significantly $(\mathrm{p}<0.01)$ higher proportion of MSM in Guntur and Hyderabad districts during R2 reported having heard of STI among Men compared to R1. However, significantly $(\mathrm{p}<0.01)$ lower proportion of MSM in Visakhapatnam (57\%) reported having heard of STI among men during R2, compared to 99\% in R1.

A higher proportion of MSM were aware of at least 2 signs/symptoms of STIs among men during R2 in the districts of E. Godavari, Hyderabad and Guntur, while their proportion significantly $(\mathrm{p}<0.01)$ declined from $96 \%$ to $52 \%$ in Visakhapatnam district.

In general, most of the MSM in all the districts in both the rounds of the study reportedly heard about HIV/ AIDS and also, were aware that the disease can be prevented. The proportion of MSM who were aware of correct methods to prevent transmission of HIV/AIDS ranged from 51\% to $72 \%$ in R2 and from $40 \%$ to $69 \%$ in R1 in the districts surveyed and most of them collected the test results. The proportion of MSM who voluntarily underwent HIV testing increased significantly $(\mathrm{p}<0.01$ ) in all the districts from $4 \%-15 \%$ in R1 to 56\% - 84\% in R2. Significantly $(\mathrm{p}<0.01)$ higher proportion $(26 \%$ - 34\%) of MSM reported having heard of Antiretroviral therapy (ART) in R2 compared to R1 (7\% - 17\%), in all the study districts except Visakhapatnam district where it declined from $17 \%$ to $4 \%$. Less than $6 \%$ in E. Godavari, Guntur and Hyderabad districts believed that ART will make people practice unsafe sex; while 76\% in Visakhapatnam believed so Table 4. 
Table 3. Distribution (\%) of MSM according to condom use-by districts.

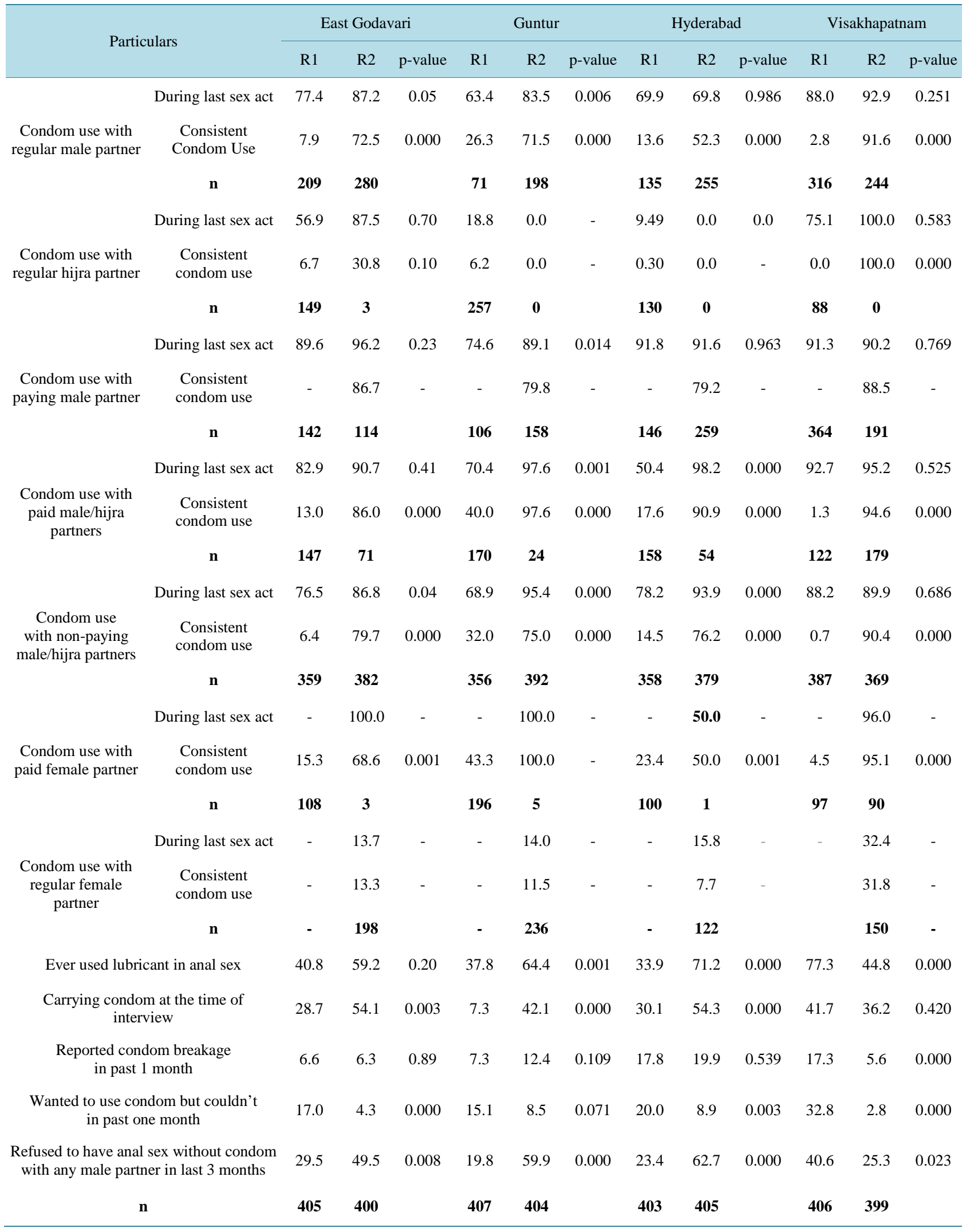


Table 4. Distribution (\%) of MSM according to knowledge of STI and HIV/AIDS—-by districts.

\begin{tabular}{|c|c|c|c|c|c|c|c|c|c|c|c|c|}
\hline \multirow{2}{*}{ Particulars } & \multicolumn{3}{|c|}{ East Godavari } & \multicolumn{3}{|c|}{ Guntur } & \multicolumn{3}{|c|}{ Hyderabad } & \multicolumn{3}{|c|}{ Visakhapatnam } \\
\hline & $\mathrm{R} 1$ & $\mathrm{R} 2$ & p-value & $\mathrm{R} 1$ & $\mathrm{R} 2$ & p-value & $\mathrm{R} 1$ & R2 & p-value & $\mathrm{R} 1$ & $\mathrm{R} 2$ & $\mathrm{p}$-value \\
\hline \multicolumn{13}{|c|}{ Knowledge of STIs } \\
\hline Heard of STI among Men & 94.0 & 91.3 & 0.29 & 82.5 & 92.1 & 0.003 & 85.4 & 92.9 & 0.020 & 99.2 & 56.7 & 0.000 \\
\hline $\begin{array}{l}\text { Have no knowledge of STI } \\
\text { symptoms among men }\end{array}$ & 8.6 & 8.8 & 0.95 & 22.0 & 9.0 & 0.000 & 18.9 & 8.1 & 0.004 & 0.9 & 46.4 & 0.000 \\
\hline $\begin{array}{l}\text { Knows at least } 2 \text { STI } \\
\text { Signs/symptoms among men }\end{array}$ & 86.6 & 91.2 & 0.19 & 71.9 & 90.9 & 0.000 & 71.3 & 91.7 & 0.000 & 95.8 & 51.8 & 0.000 \\
\hline $\mathbf{n}$ & 405 & 400 & & 407 & 404 & & 403 & 405 & & 406 & 399 & \\
\hline \multicolumn{13}{|c|}{ Knowledge of HIV/AIDS } \\
\hline Ever heard of HIV/AIDS & 99.4 & 99.5 & 0.85 & 99.7 & 99.7 & 0.978 & 100.0 & 100.0 & - & 98.7 & 92.8 & 0.014 \\
\hline $\begin{array}{l}\text { Aware that HIV/AIDS can } \\
\text { be prevented }\end{array}$ & 94.5 & 92.1 & 0.30 & 86.0 & 98.0 & 0.000 & 87.2 & 95.3 & 0.019 & 95.3 & 90.3 & 0.094 \\
\hline $\begin{array}{l}\text { Aware of correct methods } \\
\text { to prevent transmission } \\
\text { of HIV/AIDS }\end{array}$ & 51.3 & 51.3 & 1.00 & 39.6 & 56.2 & 0.010 & 41.8 & 72.0 & 0.000 & 69.3 & 62.1 & 0.255 \\
\hline $\mathbf{n}$ & 405 & 400 & & 407 & 404 & & 403 & 405 & & 406 & 399 & \\
\hline \multicolumn{13}{|c|}{ Undergone HIV testing } \\
\hline Ever undergone HIV test & 14.5 & 80.2 & 0.000 & 15.0 & 83.9 & 0.000 & 14.3 & 77.8 & 0.000 & 4.3 & 56.1 & 0.000 \\
\hline $\mathbf{n}$ & 405 & 400 & & 407 & 404 & & 403 & 405 & & 406 & 399 & \\
\hline $\begin{array}{c}\text { Undergone HIV testing } \\
\text { voluntarily }\end{array}$ & 62.3 & 67.6 & 0.61 & 54.4 & 54.5 & 0.986 & 70.0 & 53.3 & 0.072 & 30.9 & 67.5 & 0.003 \\
\hline Collected HIV test result & 87.0 & 97.3 & 0.001 & 98.0 & 97.1 & 0.695 & 78.3 & 95.4 & 0.000 & 82.6 & 99.0 & 0.000 \\
\hline $\mathbf{n}$ & 59 & 321 & & 61 & 339 & & 58 & 315 & & 18 & 224 & \\
\hline \multicolumn{13}{|c|}{ Knowledge of ART } \\
\hline Ever heard of ART & 13.6 & 26.2 & 0.01 & 13.1 & 37.1 & 0.000 & 7.4 & 34.1 & 0.000 & 17.2 & 3.7 & 0.008 \\
\hline $\mathbf{n}$ & 405 & 400 & & 407 & 404 & & 403 & 405 & & 406 & 399 & \\
\hline $\begin{array}{l}\text { Believe that ART will make } \\
\text { people practice unsafe sex }\end{array}$ & 66.6 & 6.2 & 0.000 & 18.5 & 3.0 & 0.028 & 0.0 & 5.9 & 0.512 & 57.8 & 75.8 & 0.405 \\
\hline $\mathbf{n}$ & 55 & 105 & & 54 & 150 & & 30 & 138 & & 70 & 15 & \\
\hline
\end{tabular}

\subsection{Exposure to Interventions}

Exposure to program interventions by MSM in different Rounds of the study is given in Table 5. Exposure to program intervention indicators such as "aware of Avahan NGOs", "aware of Non-Avahan NGOs", "received services from NGOs", "ever contacted by peer educator", "visited NGO clinic", "received referral services from NGOs", "member of community based organizations group" had increased significantly $(p<0.01)$ in all the districts.

\subsection{Prevalence of HIV/AIDS \& STIs}

The prevalence of HIV and STIs among MSM in different districts is presented in Table 6.

The prevalence HIV increased from $13.1 \%$ in R1 to $20.8 \%$ in R2 in Guntur and from $24.7 \%$ to $28.9 \%$ in Hyderabad districts, while it declined from $22.2 \%$ to $20.8 \%$ in E. Godavari and from $9.3 \%$ to $4.9 \%$ in Visakhapatnam districts. However, these changes were not statistically significant. 
Table 5. Exposure (\%) to program intervention by MSM—by districts.

\begin{tabular}{|c|c|c|c|c|c|c|c|c|c|c|c|c|}
\hline \multirow{2}{*}{ Particulars } & \multicolumn{3}{|c|}{ East Godavari } & \multicolumn{3}{|c|}{ Guntur } & \multicolumn{3}{|c|}{ Hyderabad } & \multicolumn{3}{|c|}{ Visakhapatnam } \\
\hline & R1 & $\mathrm{R} 2$ & p-value & $\mathrm{R} 1$ & R2 & p-value & $\mathrm{R} 1$ & $\mathrm{R} 2$ & p-value & $\mathrm{R} 1$ & $\mathrm{R} 2$ & p-value \\
\hline \multicolumn{13}{|c|}{ Exposure to interventions } \\
\hline Aware of AVAHAN NGOs & 84.8 & 100.0 & 0.12 & 12.0 & 78.1 & 0.000 & 53.7 & 0.0 & 0.000 & 94.6 & 58.6 & 0.000 \\
\hline $\begin{array}{l}\text { Aware of Avahan or } \\
\text { Non-Avahan NGOs }\end{array}$ & 84.8 & 100.0 & 0.12 & 12.0 & 78.1 & 0.000 & 53.7 & 82.4 & 0.000 & 94.6 & 58.6 & 0.000 \\
\hline $\begin{array}{l}\text { Received services from } \\
\text { Avahan/Non-Avahan NGOs }\end{array}$ & 98.0 & 100.0 & 0.000 & 98.3 & 77.7 & 0.000 & 98.6 & 81.9 & 0.000 & 100.0 & 56.4 & 0.000 \\
\hline $\begin{array}{c}\text { Contacted by Peer Educator/NGO } \\
\text { worker in last one year }\end{array}$ & 78.6 & 100.0 & 0.71 & 9.8 & 78.1 & 0.000 & 52.3 & 82.4 & 0.000 & 94.6 & 56.8 & 0.000 \\
\hline $\begin{array}{l}\text { Received condoms from } \\
\text { Peer Educator/NGO worker } \\
\text { in last one year }\end{array}$ & 76.3 & 100.0 & 0.89 & 9.8 & 77.8 & 0.000 & 51.5 & 82.2 & 0.000 & 92.8 & 56.6 & 0.000 \\
\hline Visited NGO clinic in last one year & 55.1 & 100.0 & 0.001 & 4.9 & 77.9 & 0.000 & 28.3 & 68.5 & 0.000 & 42.2 & 54.6 & 0.056 \\
\hline $\begin{array}{l}\text { Referred to other services by the } \\
\text { NGO in last one year }\end{array}$ & 9.1 & 55.8 & 0.000 & 0.0 & 76.7 & 0.000 & 3.0 & 73.4 & 0.000 & 2.3 & 36.5 & 0.000 \\
\hline Member of self help group & 6.5 & 67.1 & 0.000 & 3.3 & 73.4 & 0.000 & 5.3 & 75.4 & 0.000 & 3.1 & 41.7 & 0.000 \\
\hline Member of community group & 1.9 & 67.0 & 0.000 & 5.1 & 73.4 & 0.000 & 4.3 & 75.4 & 0.000 & 0.4 & 42.6 & 0.000 \\
\hline $\mathbf{n}$ & 405 & 400 & & 407 & 404 & & 403 & 405 & & 406 & 399 & \\
\hline
\end{tabular}

Table 6. Prevalence (\%) of HIV and STIs among MSM-by districts.

\begin{tabular}{|c|c|c|c|c|c|c|c|c|c|c|c|c|}
\hline \multirow{2}{*}{ Particulars } & \multicolumn{3}{|c|}{ East Godavari } & \multicolumn{3}{|c|}{ Guntur } & \multicolumn{3}{|c|}{ Hyderabad } & \multicolumn{3}{|c|}{ Visakhapatnam } \\
\hline & $\mathrm{R} 1$ & $\mathrm{R} 2$ & p-value & $\mathrm{R} 1$ & $\mathrm{R} 2$ & $\mathrm{p}$-value & $\mathrm{R} 1$ & R2 & p-value & $\mathrm{R} 1$ & $\mathrm{R} 2$ & p-value \\
\hline HIV infection & 22.2 & 20.8 & 0.80 & 13.1 & 20.8 & 0.066 & 24.7 & 28.9 & 0.361 & 9.3 & 4.9 & 0.053 \\
\hline Syphilis & 13.0 & 5.0 & 0.01 & 3.5 & 8.6 & 0.025 & 15.6 & 12.6 & 0.450 & 5.6 & 1.9 & 0.024 \\
\hline Chlamydia & 1.0 & 3.0 & 0.65 & 1.4 & 0.8 & 0.611 & 2.0 & 0.2 & 0.005 & 1.2 & 4.3 & 0.148 \\
\hline Gonorrhea & 0.0 & 0.0 & - & 0.5 & 0.1 & - & 0.9 & 0.5 & 0.584 & 0.5 & 0.1 & 0.210 \\
\hline $\mathbf{n}$ & 405 & 400 & & 407 & 404 & & 403 & 405 & & 406 & 399 & \\
\hline HSV-2 & 84.2 & 50.0 & 0.05 & 35.0 & 74.4 & 0.00 & 58.5 & 71.4 & 0.24 & 43.6 & 38.1 & 0.62 \\
\hline $\mathbf{n}$ & 42 & 40 & & 42 & 42 & & 41 & 40 & & 41 & 42 & \\
\hline
\end{tabular}

The prevalence of syphilis decreased significantly ( $<$ < 0.05) in E. Godavari (from 13\% to 5\%) and Visakhapatnam (6\% to 2\%) districts, while it increased from 3.5\% to 8.6\% in Guntur district, over the period.

The prevalence of Chlamydia significantly increased in Visakhapatnam district (1.2\% to 4.3\%), while similar trend was observed in the district of E. Godavari. However, the prevalence tended to decrease in the districts of Hyderabad (2\% to $0.2 \%$ ) and Guntur (1.4\% to $0.8 \%)$.

\section{Discussion}

Homosexuality, bisexuality and trans-sexuality are highly stigmatized in India. Men who have sex with men (MSM) are frequently abused; face physical violence and harassment from police and the general society [14] [17] [22]. There are limited data available in India on sexual behaviors linked to STI/HIV prevalence among MSM in Andhra Pradesh and India [18] [19] [22] [23]. The current paper presents the results from the studies that are conducted in Andhra Pradesh as part of a large scale intervention programme for the HIV prevention 
among MSM by the Avahan program. The study is unique in terms of its magnitude and numerous behavioral and biological indicators collected in the process.

Avahan Intervention started in 2006 in the select districts in Andhra Pradesh and continued till the time of the round-2 of this evaluation. The populations who participated in both rounds of this study were self-identified men having sex with men. The first round of the study was conducted in 2006 while the second round was conducted in 2009. Consistent with other studies on MSM conducted in India and elsewhere, this study revealed that most MSM were in the younger age group and therefore, were at a higher risk of acquiring and transmitting HIV infection. Mean age of the respondents who participated mean age at sexual debut during both rounds remained almost similar. Most of the participants were localities in each district, indicating lesser migration in this high-risk group compared to female sex workers.

MSM in E. Godavari district shows a new trend of 9\% staying with male partners, which is unusual in India and such behaviours carry a lot of stigma and discrimination. This can be result of the significant increase in community mobilization and empowerment activities like the community based groups seen in the district.

Condom use with all types of male partners (regular, main and commercial) increased significantly from round-1 of the study showing a clear impact of the interventions in changing behaviors. However, there has been a significant increase in the number of commercial partners across the districts, which might be indicating to a new trend of commercial sex among MSM, which according to other studies has been lower till date [21] [22], since sex among MSM had been mostly for pleasure and not for monetary gains [14] [24] [25]. About 45\% of the MSM in Visakhapatnam district reported having a paid male/hijra partner, which is significantly higher than the earlier round and an increasing trend of having paying male partners is seen in Guntur and Hyderabad.

Many studies did indicate that MSM was more difficult to reach; which was always perceived as a bigger challenge for interventions [14] [15] [17] [25]. Results from this study however show a mixed result. While E. Godavari, Guntur and Hyderabad districts showed nearly $80 \%$ to $100 \%$ outreach by the program for condom distribution and clinical services, while Visakhapatnam districts showed lesser than $60 \%$ exposure to the program intervention. Interestingly, Visakhapatnam district had the highest program participation rates during R1, compared to R2.

A significant proportion of MSM reported having regular female partner during both the rounds of the study and the consistent condom use by MSM with these partners remained low during both the rounds, indicating high risk behavior. Impact of behavior change interventions is not seen in this regard, which could be because the program does not focus much on this aspect or because of social stigma. This is a crucial indicator for preventing the spread of HIV in the state. In addition, not all MSM use condom with their male partners. Thus, there exists potential risk of the bridge group spreading HIV to population at large.

Although an overwhelming majority of the respondents had heard of AIDS/HIV, only about $50 \%$ to $70 \%$ of them had correct knowledge on HIV. Knowledge in STIs among men was observed to be low in Visakhapatnam district in R2, compared to R1. High levels of knowledge about prevention of HIV/AIDS or STI alone is not enough to prevent risky behavior, unless attitudes also change [25].

Though the HIV prevalence during R2 decreased in Visakhapatnsm, a significant increase was observed in the district of Guntur, while it remained high in the districts of E. Godavari, and Hyderabad, which was a matter of concern and needed to be further investigated. The prevalence of Chlamydial infection, though low increased during R2 in Visakhapatnam, but tended to decrease in other districts. The prevalence of syphilis during R2 increased two-fold in Guntur district, while it tended to decrease in the remaining districts.

HIV prevention programs in Andhra Pradesh need better focus on condom use MSM with female partners, and imparting knowledge on HIV/AIDS prevention. Program needs to take note of the increasing trend in having commercial sex. There is an urgent need to focus on the Visakhapatnam district as the program exposure and STI knowledge among the MSM is low. Though the HIV prevalence is among MSM in Visakhapatnam, in view of the low exposure to interventions, there is need to strengthen IEC activity to control the spread of the infection.

The findings in the study are subject to certain limitations. First, a sample size of 400 was considered for MSM at district level. Though this size is adequate to provide sufficiently precise estimates for high prevalence indicators such as condom use, it may be inadequate to precisely estimate other indicators such as HIV or STI prevalence. Self-identified MSM do not represent the whole MSM population and in the present study, only self-identified MSM contacted in the hot spots during the survey period are included as respondents. 


\section{Acknowledgements}

Support for this study was provided by the Bill \& Melinda Gates Foundation through Avahan India AIDS Initiative as a grant to FHI.

The authors do not have any conflict of interest. GNVB conceived and supervised the study. KV involved field supervision, development of database, carried out the statistical analysis and prepared the manuscript. HK \& SPV monitored supervised the field operations. HR supervised lab estimations and SK supervised the field operations and provided critical comments. All authors read \& approved the final version of the manuscript. The authors thank all the MSM respondents who participated in the study. The authors thank Dr. B. Sesikeran, Director, National Institute of Nutrition, for permission to conduct the study.

\section{References}

[1] HIV Declining in India. New Infections Reduced by 50\% from 2000-2009. Sustained Focus on Prevention Required, Government of India Ministry of Health \& Family Welfare, Department of AIDS Control National AIDS Control Organisation.

[2] (2008) HIV Sentinel Surveillance and HIV Estimation in India 2007, a Technical Brief. NACO.

[3] Pisani, E., Girault, P., Gultom, M., Sukartini, N., Kumalawati, J., Jazan, S., et al. (2004) HIV, Syphilis Infection, and Sexual Practices among Transgenders, Male Sex Workers, and Other Men Who Have Sex with Men in Jakarta, Indonesia. Sexually Transmitted Infections, 80, 536-540. http://dx.doi.org/10.1136/sti.2003.007500

[4] Beyrer, C., Eiumtrakul, S., Celentano, D.D., Ruckhpaophunt, S., Nelson, K.E. and Khamboonruang, C. (1995) Same Sex Behavior, Sexually Transmitted Diseases, and HIV Risks among Young Northern Thai men. AIDS, 9, 171-176. http://dx.doi.org/10.1097/00002030-199509020-00009

[5] Choi, K.-H., Liu, H., Guo, Y., Han, L., Mandel, J.S., Rutherford, G.W., et al. (2003) Emerging HIV-1 Epidemic in China in Men Who Have Sex with Men. Lancet, 361, 2125-2126. http://dx.doi.org/10.1016/S0140-6736(03)13690-2

[6] Asthana, S. and Oostvogels, R. (2001) The Social Construction of Male "Homosexuality” in India: Implications for HIV Transmission and Prevention. Social Science \& Medicine, 52, 707-721. http://dx.doi.org/10.1016/S0277-9536(00)00167-2

[7] Colby, D.J. (2003) HIV Knowledge and Risk Factors among Men Who Have Sex with Men in Ho Chi Minh City, Vietnam. Journal of Acquired Immune Deficiency Syndromes, 32, 80-85. http://dx.doi.org/10.1097/00126334-200301010-00012

[8] Khan, O.A. and Hyder, A.A. (1998) HIV/AIDS among Men who Have Sex with Men in Pakistan. Sexual Health Exchange, 2, 12-15.

[9] van Griensven, F., Supawitkul, S., Kilmarx, P.H., Limpakarnjanarat, K., Young, N.L., Manopaiboon, C., et al. (2001) Rapid Assessment of Sexual Behavior, Drug Use, HIV, and STD in Northern Thai Youth Using Audio-Computer-Assisted Self-Interviewing and Noninvasive Specimen Collection. Pediatrics, 108, E13. http://dx.doi.org/10.1542/peds.108.1.e13

[10] Van Griensven, F., Kilmarx, P.H., Jeeyapant, S., Manopaiboon, C., Korattana, S., Jenkins, R.A., et al. (2004) The Prevalence of Bisexual and Homosexual Orientation and Related Health Risks among Adolescents in Northern Thailand. Archives of Sexual Behavior, 33, 137-147. http://dx.doi.org/10.1023/B:ASEB.0000014328.49070.8c

[11] Go, V.F., Srikrishnan, A.K., Sivaram, S., Murugavel, G.K., Galai, N., Johnson, S.C., Sripaipan, T., et al. (2004) High HIV Prevalence and Risk Behaviors in Men Who Have Sex with Men in Chennai, India. Journal of Acquired Immune Deficiency Syndromes, 35, 314-319. http://dx.doi.org/10.1097/00126334-200403010-00014

[12] Manopaiboon, C., Kilmarx, P.H., Limpakarnjanarat, K., Jenkins, R.A., Chaikummao, S., Supawitkul, S. and van Griensven, F. (2003) Sexual Coercion among Adolescents in Northern Thailand: Prevalence and Associated Factors. Southeast Asian Journal of Tropical Medicine and Public Health, 34, 447-457.

[13] Beyrer, C., Sripaipan, T., Tovanabutra, S., Jittiwutikarn, J., Suriyanon, V., Vongchak, T., et al. (2005) High HIV, Hepatitis C and Sexual Risks among Drug-Using Men Who Have Sex with Men in Northern Thailand. AIDS, 19, 1535-1540. http://dx.doi.org/10.1097/01.aids.0000183122.01583.c7

[14] Khan, S. (1996) Under the Blanket: Bisexualities and AIDS in India. In: Aggleton, P., Ed., Bisexualities and AIDS: International Perspectives, Taylor and Francis, London, 161-177.

[15] Khan, S. (2001) Culture, Sexualities and Identities: Men Who Have Sex with Men in India. Journal of Homosexuality, 40, 99-115. http://dx.doi.org/10.1300/J082v40n03 06

[16] Vinay, K., Sanjeevanee, K., Neelima, S. and Meghana, M. (2000) Networks, Language, and Sexual Behaviors of Men Who Have Sex with Men in an Urban Setting. Workshop on Reproductive Health in India, New Evidence and Issues, 
Pune.

[17] Asthana, S. and Oostvogels, R. (2001) The Social Construction of Male Homosexuality in India: Implications for HIV Transmission and Prevention. Social Science \& Medicine, 52, 707-721. http://dx.doi.org/10.1016/S0277-9536(00)00167-2

[18] Dandona, L., Dandona, R., Kumar, G.A., Gutierrez, J.P., McPherson, S. and Bertozzi, S.M., the ASCI FPP Study Team (2006) How Much Attention Is Needed towards Men Who Sell Sex to Men for HIV Prevention in India? BMC Public Health, 6, 31. http://dx.doi.org/10.1186/1471-2458-6-31

[19] Dandona, L., Dandona, R., Gutierrez, J.P., Kumar, G.A., McPherson, S. and Bertozzi, S.M., the ASCI FPP Study Team (2005) Sex Behaviour of Men Who Have Sex with Men and Risk of HIV in Andhra Pradesh, India. AIDS, 19, 611-619. http://dx.doi.org/10.1097/01.aids.0000163938.01188.e4

[20] Chandrasekran, P., Dallabeta, G., Loo, V., Mills, S., Saidel, T., Adhikary, R., et al. (2008) Evaluation Design for Large-Scale HIV Prevention Programs: The Case of Avahan, the India AIDS Initiative. AIDS, 22, S1-S15.

[21] Dowsett, G., Grierson, J. and McNally, S. (2006) A Review of Knowledge about the Sexual Networks and Behaviours of Men Who Have Sex with Men in Asia. Australian Research Centre in Sex, Health and Society, La Trobe University, Melbourne.

[22] Verma, R.K. and Collumbien, M. (2004) Homosexual Activity among Rural Indian Men: Implication for HIV Interventions. AIDS, 18, 1845-1847. http://dx.doi.org/10.1097/00002030-200409030-00014

[23] Schneider, J.A., Saluja, G.S., Oruganti, G., Dass, S., Tolentino, J., Laumann, E.O., et al. (2007) HIV Infection Dynamics in Rural Andhra Pradesh South India: A Sexual-Network Analysis Exploratory Study. AIDS Care, 19, 1171-1176. http://dx.doi.org/10.1080/09540120701336392

[24] Narain, A. and Dutta, B. (2007) "Male-to-Male Sex, and Sexuality Minorities in South Asia," by the Alternative Law Forum. UNAIDS Conference on "Risk and Responsibility”, 26 September 2006.

[25] MSM and HIV/AIDS Risk in Asia (2006) What Is Fueling the Epidemic among MSM and How Can It Be Stopped? Treat Asia Special Report, August 2006. 
Scientific Research Publishing (SCIRP) is one of the largest Open Access journal publishers. It is currently publishing more than 200 open access, online, peer-reviewed journals covering a wide range of academic disciplines. SCIRP serves the worldwide academic communities and contributes to the progress and application of science with its publication.

Other selected journals from SCIRP are listed as below. Submit your manuscript to us via either submit@scirp.org or Online Submission Portal.
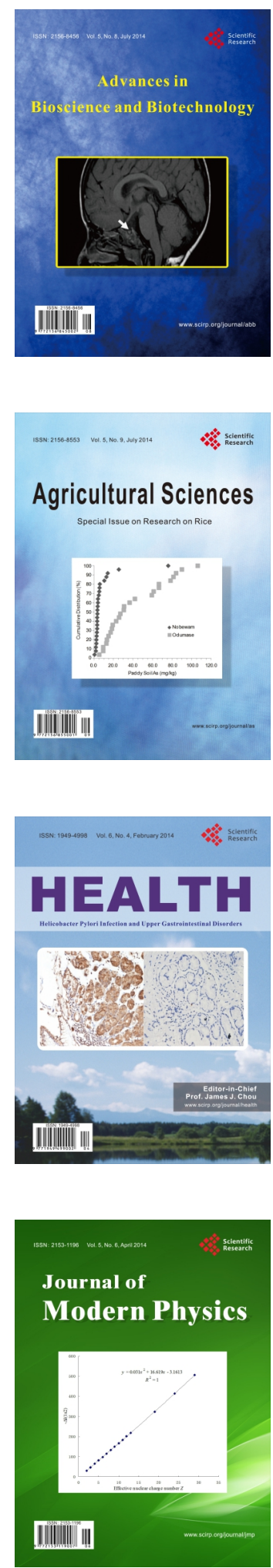
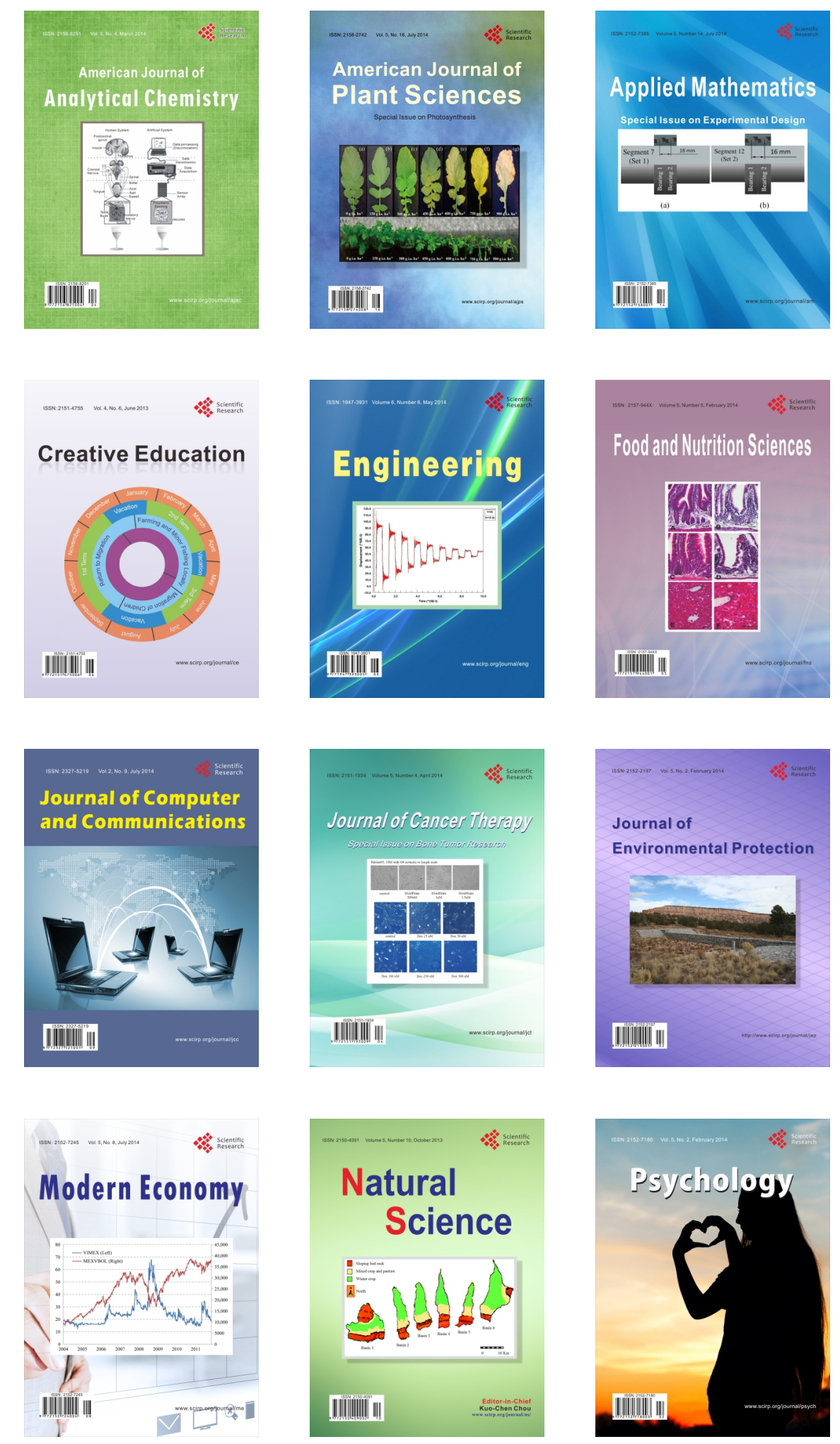